\title{
The Slope Stability Evaluation of Open-pit Mine Based on GIS Shiguo Sun ${ }^{1, a}$, Zizhen Miao ${ }^{2, b}$, Yanfei Dong ${ }^{3, c}$ and Yanyan $\mathrm{He}^{4, \mathrm{~d}}$ 1,2,3,4 No.5 Jin Yuan Zhuang Road, Shi Jing Shan District, Beijing, China assg981@163.com, ${ }^{\mathrm{b}} 406818699 @ q q . c o m,{ }^{c}$ dongyanfei1990@163.com
}

Keywords: Stability evaluation, Open-pit mine slope, GIS

Abstract: The various influence factors of the slope stability is analyzed on the slope stability problems. Based on the basic principle and method of fuzzy mathematics and GIS, the slope stability analysis of fuzzy and comprehensive evaluation model is established and the grading index of the slope stability is determined. By analyzing an example of large open-pit mine slope engineering, the district stability of this slope is evaluated. The results suggest this evaluation model can evaluate the regional slope stability, and the evaluation result is reasonable.

\section{Introduction}

The basic principle of fuzzy partition evaluation based on GIS is to give the evaluation factors of each unit in the grids corresponding attribute values, each factor has the specific properties of raster graphics. With GIS superposition analysis technique, each grid attribute weights composite analysis to produce the new grid attribute, according to which computer classifies regionalization, and the value evaluation results are obtained then. Slope stability evaluation is a comprehensive valuation on the research in slope engineering.

Not only factors affecting the stability of slope are numerous and complex, but the influence degree of various factors are also different. Furthermore, level indexes and boundaries of slope stability are too vague to distinguish, which makes it hard to build classic unified mathematics models and mechanics models to measure. Therefore, a fuzzy comprehensive evaluation model of slope stability which is based on the basic principle and method of fuzzy mathematics is established in this paper, and shows comprehensive evaluation about the stability with an open-pit Mine slope engineering.

\section{The Establishment of the Fuzzy Comprehensive Evaluation Model ${ }^{[1-2]}$}

Before establishing the fuzzy comprehensive evaluation model of slope stability, two fuzzy subsets should be determined. One is the analysis of grade set used $\mathrm{D}$ to represent, $D=\left[D_{1}, D_{2}, \cdots, D_{m}\right]$.The other is a the analysis of index set used $\mathrm{E}$ to represent, $E=\left[E_{1}, E_{2}, \cdots, E_{n}\right]$, so this constitutes several indicators to determine the level of each analysis. Each index factor has $m$ sets of states and a total of $n$ factors, used $U_{1}, U_{2}, \cdots, U_{n}$ to indicate respectively, and $U_{i}=\left[U_{i 1}, U_{i 2}, \cdots, U_{i m}\right]^{T}, i=1,2, \cdots, r$. Thus stability analysis mathematical model is got:

$$
U=\left[\begin{array}{cccc}
U_{11} & U_{12} & \cdots & U_{1 n} \\
U_{21} & U_{22} & \cdots & U_{2 n} \\
\vdots & \vdots & \ddots & \vdots \\
U_{m 1} & U_{m 2} & \cdots & U_{m m}
\end{array}\right]
$$

The above mathematical model is given values of classification membership function $p_{i}=(i=1,2, \cdots, m)$, and then according to the relationship and the importance among the index factors, weight $g_{i}(i=1,2, \cdots, n)$ is assigned. A fuzzy relationship is set up: 


$$
U=\left[\begin{array}{l}
g_{1} P_{1}, g_{2} P_{1} \ldots g_{n} P_{1} \\
g_{1} P_{2}, g_{2} P_{2} \ldots g_{n} P_{2} \\
\ldots \ldots \ldots \ldots \ldots \ldots . . . \ldots \ldots \\
g_{1} P_{m}, g_{2} P_{m} \ldots g_{n} P_{m}
\end{array}\right]
$$

\section{The Influence Factors of the Slope Stability}

According to the existing research results ${ }^{[3-4]}$, factors affecting the stability of slope are very complex. A comprehensive analysis of factors affecting the stability of slope is mainly having several aspects:

1. The rock types of the slope

Nature of the slope rock mass is the essential element determining the magnitude of slope sliding resistance. Hard intact rocks can form a very steep slope and keep stable; however the weak rock or soil can only form a relatively low slope. Slope lithology is composed of different generations of strata, so the lithology is different.

2. The erosion degree of rock mass

Under the action of various forces rock mass's structure will change, which leads to change of rock mass mechanics properties. In some serious cases, this makes engineering geological performance deterioration, bad to the slope engineering.

3. The slope height and the slope angle

Both the slope angle and the slope height have different degrees of influence to the stability of the slope. The bigger the slope angle is, or the higher the slope height is, the worse the slope stability degrees will be.

4. The structure of rock mass

Rock mass structure refers to the permutation and combination of structural planes and structure form in rock mass, through the analysis of the structural plane and the structure body, further accurate measure of the slope stability.

\section{Fuzzy Partition Evaluation Based on GIS}

GIS has powerful data processing function, according to the geological data and engineering experience, once the influence factors of slope stability is added in the GIS system and the weighting factors are endowed, the slope stability analysis and database can be established. Combined with the attribute database and space database of geological data, the slope stability analysis based on fuzzy evaluation can be realized.

In accordance with the requirements of GIS, the engineering geological map should process hierarchically well, which make it convenient to create graphics database. All elements should be in the same layer. Using correlation function of GIS, the effective information is extracted from the engineering geological map, the geographical database is established, and the induction and integration of different rock properties are realized. Corresponding influence factors in the database can be converted to raster graphics (as shown in Fig. 1-5), makes the foundation for GIS raster overlay analysis. 


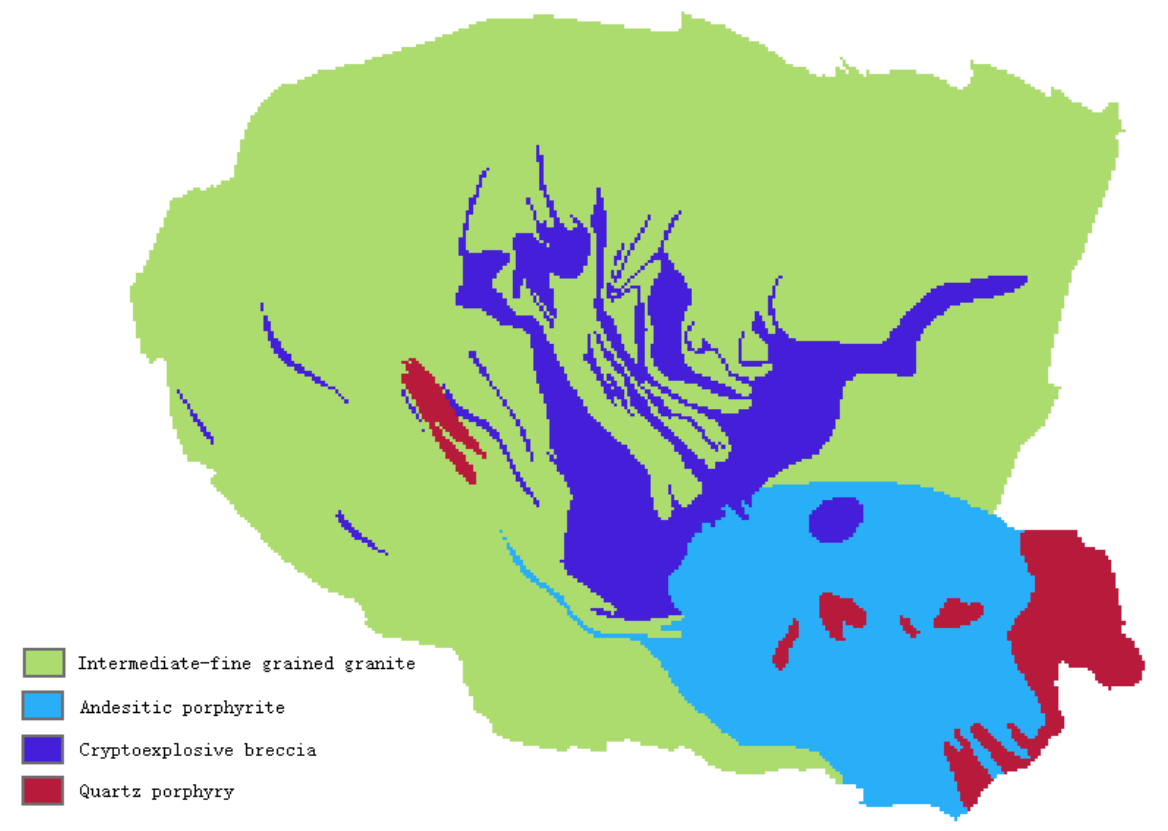

Fig.1 Rock type factors of GIS raster map

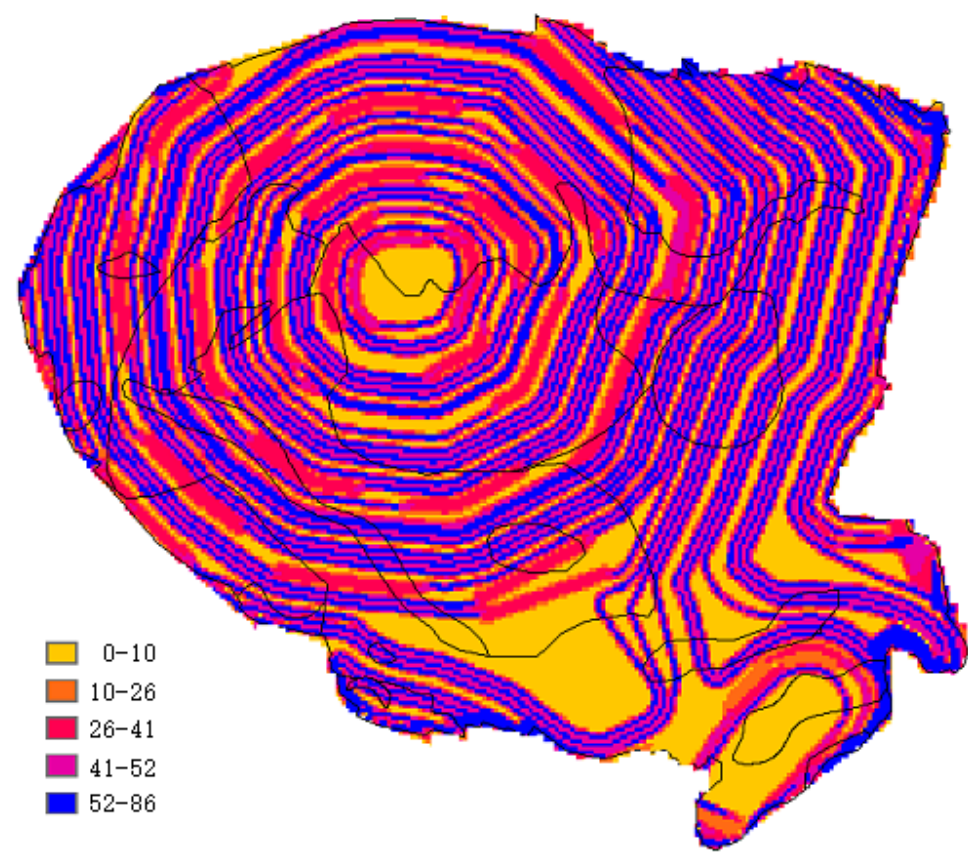

Fig.2 Slope angle factors of GIS raster map 


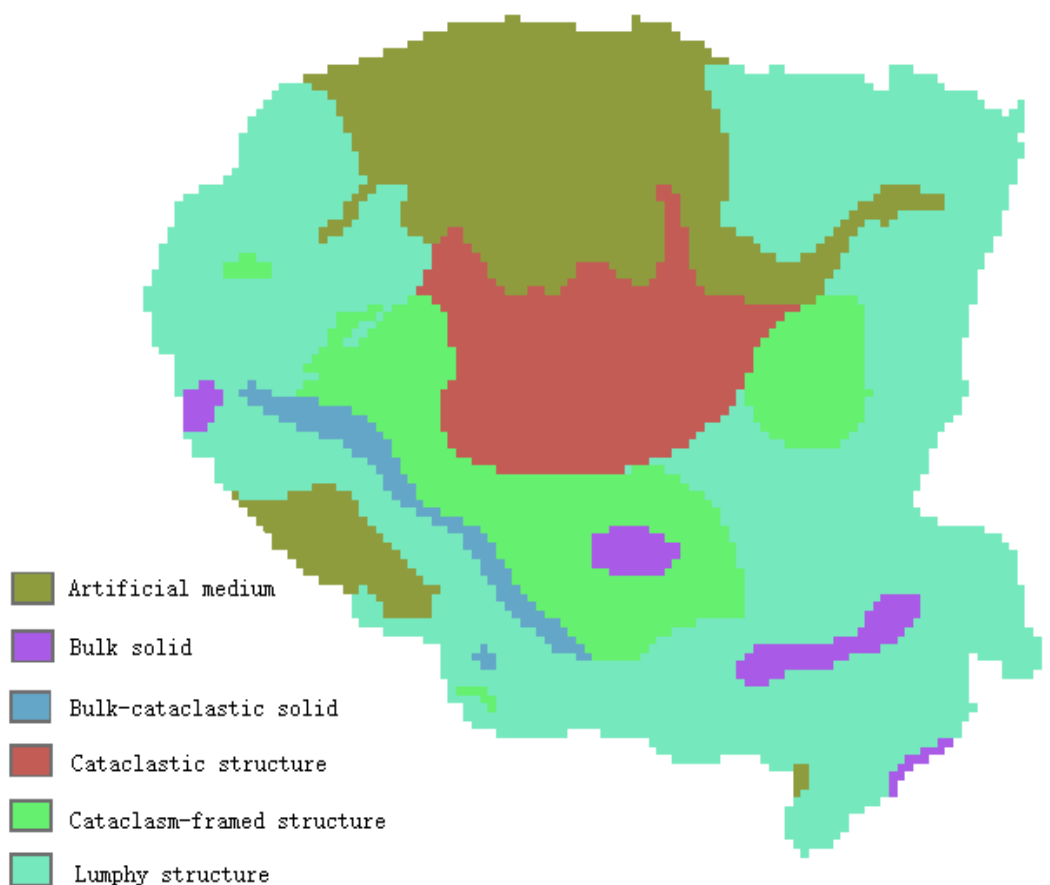

Fig.3 Rock mass structure factors of GIS raster map

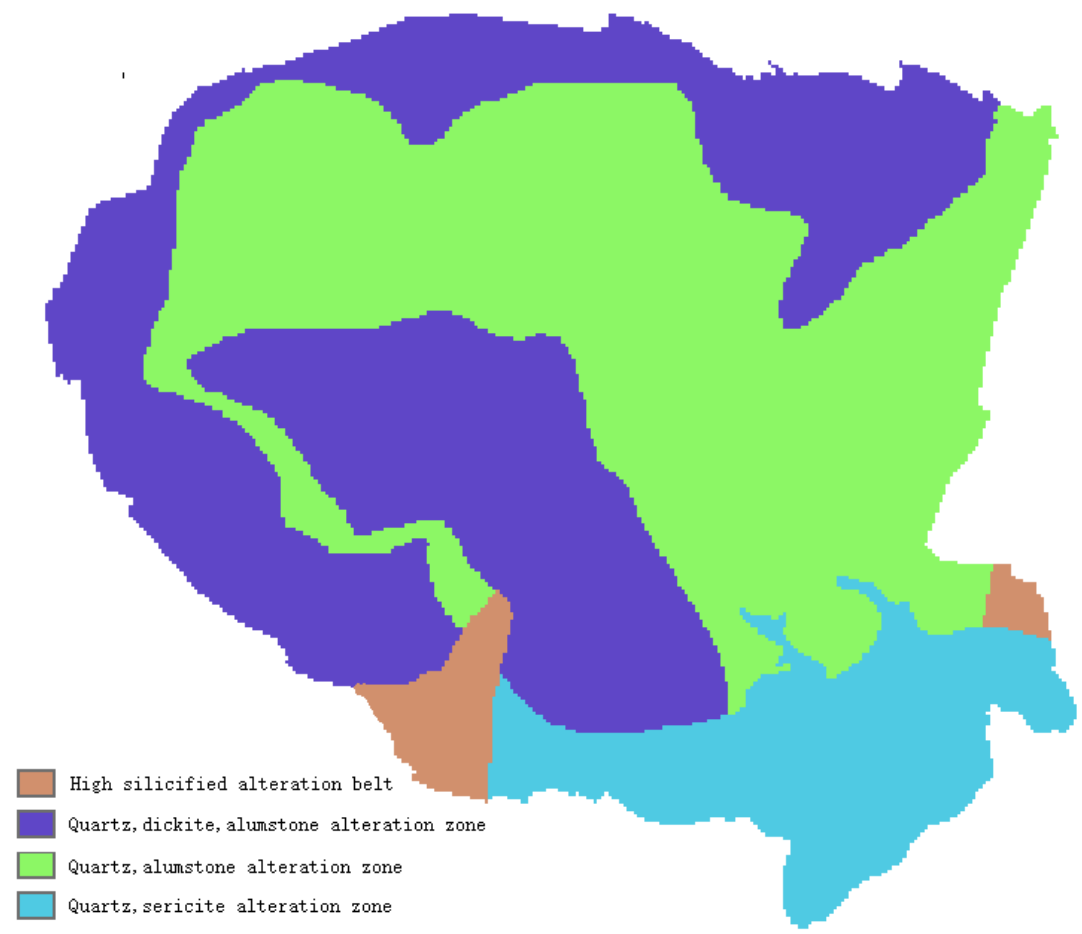

Fig.4 Rock weathering alteration factor GIS raster map 


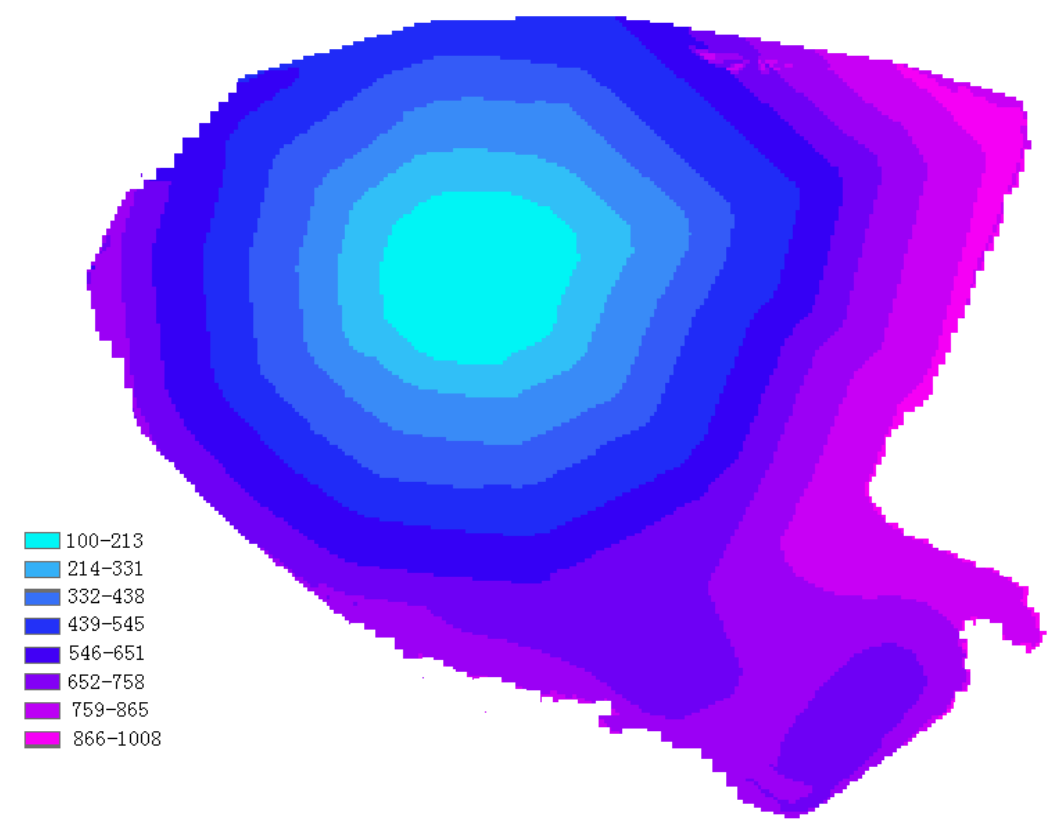

Fig.5 The rock mass elevation factor of GIS raster map

Fig. 1 shows the rock type factors of raster map based on GIS. Fig. 2 shows slope angle factors of raster map based on GIS. Fig.3 shows rock mass structure factors of raster map based on GIS. Fig.4 shows rock weathering alteration factor GIS raster map based on GIS. Fig.5 shows the rock mass elevation factor of raster map based on GIS. After rasterizing the data, the next step is grid computing and overlay analysis.

With the help of Spatial Analyst Raster Calculator tools of ArcGIS software, the index factors of grid figure weighted superposition are completed. Its computation formula is

$$
Z=\sum_{i=1}^{7} \omega_{i} C_{i}=0.349 C_{1}+0.255 C_{2}+0.236 C_{3}+0.099 C_{4}+0.06 C_{5}
$$

Eventually, the result of the slope stability zoning is shown in Fig. 6.

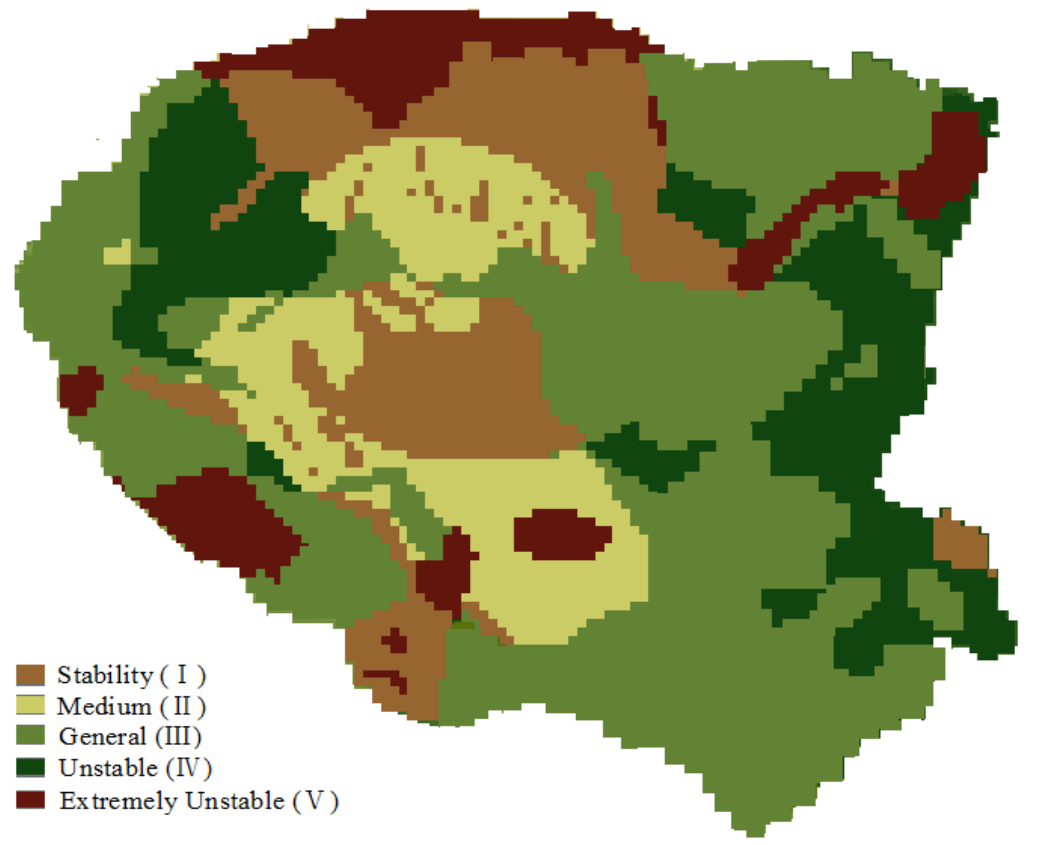

Fig.6 The slope stability fuzzy partition evaluation results of open-pit mine 


\section{Summary}

1. Combining the theory method and GIS technology, it's better to show the result of slope stability evaluations and also has great significance to the actual engineering. It can be compared with other evaluation methods results synthetically to come to the conclusion that is more in line with the actual situation, which makes a truly objective evaluation of slope stability.

2.Due to the factors effecting the stability of slope are very complex, and many factors have randomness and uncertainty, therefore, the slope stability analysis belongs to the uncertainty problem, which this paper suggests that using fuzzy comprehensive evaluation to analyze it.

3. The analysis of large open-pit mine slope engineering shows that this evaluation method is correct and the evaluation result is reasonable, which have certain reference and application value.

\section{Acknowledgments}

The First Author: ShiguoSun (1959- ), male,Postdoctoral. The professor of the northern industrial university majoring in civil engineering construction engineering college level discipline responsibility, doctoral supervisor. Mine safety and the northern industrial university institute of geotechnical engineering.

Fund Project: This research has been funded by The National Natural Science Foundation of China (No.41172250), National five-year science and technology support project (2012BAK09B06),The innovative team project of Beijing (IDHT20140501), The scientific research base construction, scientific research innovation platform, scientific research and special - impact pressure build of microseismic monitoring and early warning system (XN083) and New type of anchor reinforcement technique field test research and graduate student ability training (XN107).

\section{References}

[1]Xinmin Wang, Qian Kang, Jianchun Qin,etc. Application of AHP-extenics model to safety evaluation of rock slope stability, J. Journal of Central South University (Science and Technology). Vol. 44(2013), p. 2455-2462.

[2]Yuansong Li, Wenfeng Chen, Xinping Li, etc. Stability assessment of rock slope based on fuzzy neural network, J. Journal of Wuhan University of Technology. Vol. 35 (2013), p. 113-118.

[3]Shiguo Sun, Yanfei Dong. The slope stability evaluation of open-pit mine based on matter-element extension theory , J. Nonferrous Metals(Mining Section). Vol. 65 (2015), p. 100-102.

[4]Leilei Liu, Shaohe Zhang, Limao Liu. AHP ideal point model of rock slope stability classification and applications, J. Journal of Central South University: Natural Science, Vol. 45 (2014), p. 3499-3503. 